\title{
A Christmas Story
}

\author{
Jeffrey J. Skubic ${ }^{1,2}$ \\ ${ }^{1}$ Trauma Medical Director, DHR Health, Edinburg, TX, USA \\ ${ }^{2}$ Assistant Professor of Surgery, The University of Texas at Rio Grande Valley - School of Medicine, \\ Edinburg, TX, USA
}

E-mail: j.skubic@dhr-rgv.com

Received 12/03/2020

Accepted for publication 01/28/2021

Published 03/05/2021

Keywords: Trauma; Injury; Emergency; Surgery;

It is Christmas night at your house at 2100 hours. Everyone is all sitting around the house lounging, enjoying themselves after a long well deserved Christmas feast. Giggling erupts from the living room, where all the children of the extended family are watching holiday cartoons. Frank Sinatra sings for his supper on the radio in the distant kitchen, while a large crackle erupts from the beautifully cut logs in the fireplace. Suddenly there is a loud boom, boom, and thud. The crash is heard from the front stairwell. After quickly placing your glass of port down, you rush to the front of the house only to find your beloved 80 -year-old uncle on the hardwood floor face down. After you carefully roll him over, you note a swollen right face and very deformed nose. Your astutely peel open his right eye and note that he does not have full motion of his right eye. Feeling the effects of the alcohol, you ask your brother, who does not drink, to drive both of you to the hospital immediately. You assist your uncle to the car and have him hold an ice pack to his face the entire ride. At the hospital emergency room (ER), the emergency physician and trauma surgeon on call examine your uncle. After examining him and performing a CT they share the news that your uncle has a severely deformed nasal fracture, a severe right orbital fracture, and real concern for nerve entrapment. He also has a small subdural hematoma that needs to be watched. The trauma surgeon then shares the dreaded news with you: There are no appropriate surgeons on call that night; they are going to prepare to transfer your uncle 250 miles to San Antonio, where the appropriate trauma team and surgeons will be waiting to receive him.

You, as a healthcare worker, will you demand that they keep your uncle here? Will you stamp your feet and demand they call each surgeon and find someone willing to come in? Will you call the physician administrator on-call, complain that this is unacceptable, and demand they find a surgeon? Will you, yourself, retrieve your cell phone from your jacket and call your colleagues demanding that one of them come to the hospital immediately to operate on your family member. Despite trying all, your uncle is loaded on a helicopter and is gone. You share your frustration with your family.

Unfortunately, we and many others are faced with this awkward scenario. But why should this occur in 2020 in one of the more advanced countries in the world? The answer lies in an understanding that trauma is a disease, and the trauma patient requires the appropriate care from the appropriate facility as quickly as possible to treat their disease. That is the case for myocardial infarction and a cerebral bleed. The same is true for the trauma victim; why should they be treated any less? For this to occur, we need to have the level of care near the trauma patient with the resources to care for the victim 24/7 completely. Trauma, like all other diseases, knows no limits!

Your family asks you, "What should our uncle really get?"

"He needs a 'level one' here!"

"A what?" they ask.

"A level one Trauma Center. Let me explain:"

Trauma centers in the United States are identified in two fashions: A designation process and a verification process. The different levels (i.e. Level I, II, III, IV or V) refer to the resources available in a trauma center and the number of patients admitted yearly. These are categories defined by national standards for trauma care in hospitals. The categorization area is also unique to both adult and pediatric 
facilities. The Trauma Center designation is a process outlined and developed at a state or local level. The state or local municipality identifies unique criteria in which to categorize Trauma Centers. These categories vary from state to state and are typically outlined through legislative or regulatory authority. Trauma Center Verification is an evaluation process done by the American College of Surgeons (ACS) to evaluate and improve trauma care. The ACS does not designate trauma centers; instead, it verifies the presence of the resources listed in Resources for Optimal Care of the Injured Patient. These include commitment, readiness, resources, policies, patient care, performance improvement, education, and research. Verification is a voluntary process by the Trauma Center, and if verified, it lasts for a 3-year period. Let me outline the common criteria for a Level One Trauma Center as verified by the ACS and also designated by states.

Level I Trauma Center is a comprehensive regional resource that is a tertiary care facility central to a trauma system. A Level I Trauma Center is capable of providing total care for every aspect of injury - from prevention of the injuries through to the rehabilitation. In fact, rehabilitation is the key to the victim making a complete recovery. The key resources of a Level I Trauma Centers include 24-hour in-house coverage by trauma (general) surgeons and prompt availability of care in specialties such as orthopedic surgery, neurosurgery, anesthesiology, emergency medicine, radiology, internal medicine, plastic surgery, oral and maxillofacial, hand surgery, cardiac surgery, thoracic surgery, vascular surgery, obstetrics and gynecology, ophthalmology, urology and critical care. They are a referral resource for communities in nearby regions. They provide leadership in the prevention, public education to surrounding communities, and continuing education to their trauma team members. Level one trauma centers incorporate a comprehensive quality assessment program to keep their trauma care at a high level of performance. They provide organized teaching and research effort to help direct new innovations in trauma care particularly unique to the community they serve. Importantly they have programs for substance abuse screening and patient intervention. Finally, they need to meet a minimum requirement for the annual volume of severely injured patients to keep their trauma team experienced and always ready.

In our uncle's case, he is best served in such a center with all the resources listed above available to him. He has multiple injuries and an ongoing injury of concern. He will require surgery and maybe even a second surgery. Then he will need post-operative care and rehabilitation to get him back to his quality of life. He needs an experienced team that can provide his trauma care immediately and not far from his home. Sadly we don't have that here.
So why should anyone not be provided with that level of care? As the New Year comes, let us continue to push to have a level one trauma center in the Rio Grande Valley. Let us not have to repeat this Christmas story. In the New Year let us treat our trauma victims the way they should be, and here at home.

\section{Diclosures}

JJS declares no conflicts of interest.

\section{References}

No references used in this document.

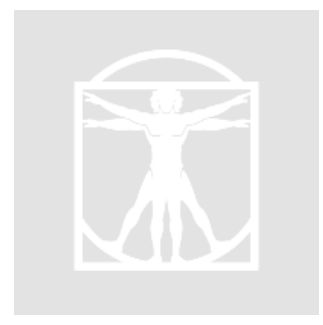

